\title{
Numerical simulation of stress relieving and analysis of influencing factors on geostress measurement
}

\author{
ZHAO Tongbin ${ }^{1,2,3}$ ZHANG Minglu ${ }^{1,3}$ LI Zhanhai ${ }^{1,3}$ ZHANG Ze ${ }^{3}$ \\ (1. State Key Laboratory Breeding Base for Mining Disaster Prevention and Control, Shandong University of \\ Science and Technology, Qingdao, Shandong 266590, China; \\ 2. Heilongjiang Ground Pressure \& Gas Control in Deep Mining Key Lab, Heilongjiang University of Science \\ and Technology, Harbin, Heilongjiang 150027, China; 3. College of Mining and Safety Engineering, Shandong \\ University of Science and Technology, Qingdao, Shandong 266590, China)
}

\begin{abstract}
At present, over coring method by using hollow inclusion strain cells are applied widely for geostress measurement. But there are some errors in measurement accuracy. In order to improve the measurement precision and reliability of stress relief method, the paper analyzed the influence of drilling aperture ratio on stress. Studies shows that drill holes will cause the loss of displacement and change the aperture ratio of the drilling will cause variation of losing displacement and correction coefficient $K_{1}$. The equation of losing displacement and drilling ratio is $\beta=0.5546 r^{(-1.856)}+0.06$. Finally, using simulated conclusions analyzed geostress measurement data of Datai mine and verified the validity and feasibility of the formula, It can provides reference for field measurement precision.
\end{abstract}

Keywords: Stress relief Method; Drilling aperture ratio; geostress measurement; Numerical simulation

\section{Introduction}

Geostress is the natural stress deposited in the rock strata of the earth's crust and is the important influencing factor for the rock mass deformation and failure in mine, water conservancy, hydropower, civil construction and other kinds of projects. In addition, it use to determine rock mechanics parameters , analyze rock mass stress and design supporting ${ }^{[1-2]}$.In engineering, generally through on-site measurements to get the size and direction of geostress ${ }^{[3]}$. At present, stress relief method is widely used to measure geostress .The method is simple, adaptable. It can determine the three-dimensional stress state of the measuring point. But stress relief method still exist errors in the measurement accuracy, many scholars studied the factors affecting the precision of the measurement ${ }^{[4-7]}$. But the strain gauge position and drilling aperture ratio's impact on measurement accuracy is not perfect. In this paper will research the numerical simulation method for stress relief process and analyze the impact of different aperture ratio, then will analyze stress measurement results of Datai mine with the conclusion.

2. The principle of geostress measurement by hollow inclusion strain cells

The method of hollow inclusion strain cells is widely used among stress relief methods, which is shown in Fig.1. This kind of strain gauge is recommended by ISRM, and is designed for monitoring during the core stress release process. Its principle is that in rock mass's(having a 3-D ground stress) drilling hole wall of adhesive elastic circle layer, assuming the rock mass is linear elastic. When the surrounding rock is cut by overcoming, geostress is calculated by using elastic recovery ${ }^{[8]}$, as shown in Fig.2.

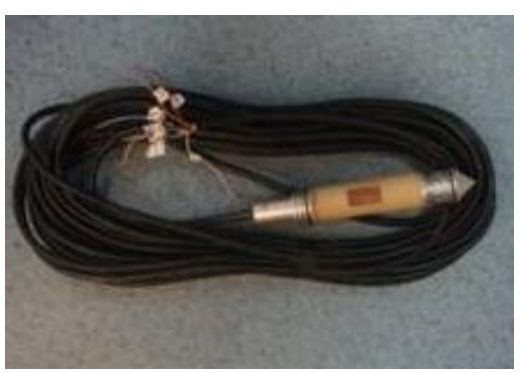

Fig.1 Hollow Inclusion Strain Cells 


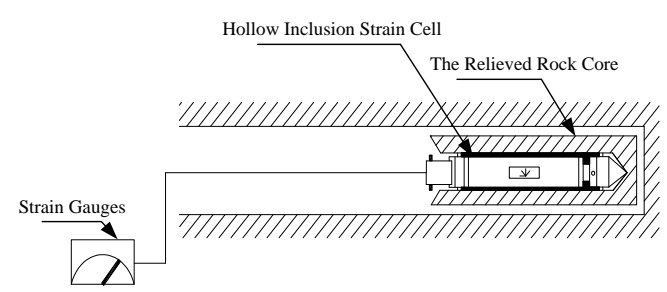

Fig.2 Stress Relief Process of Hollow Inclusion Strain Cell

The hollow inclusion stresses relieve strain gauges measured during the stress-strain data to calculate the formula are:

$$
\begin{aligned}
& \varepsilon_{\theta}=\frac{1}{E}\left\{\left(\sigma_{x}+\sigma_{y}\right) k_{1}+2\left(1-v^{2}\right)\left[\left(\sigma_{y}-\sigma_{x}\right) \cos 2 \theta\right.\right. \\
& \left.\left.-2 \tau_{x y} \sin 2 \theta\right] k_{2}-v \sigma_{z} k_{4}\right\} \\
& \varepsilon_{z}=\frac{1}{E}\left[\sigma_{z}-v\left(\sigma_{x}+\sigma_{y}\right)\right] \\
& \gamma_{\theta z}=\frac{4}{E}(1+v)\left(\tau_{y z} \cos \theta-\tau_{z x} \sin \theta\right) k_{3}
\end{aligned}
$$

Where, $\varepsilon_{\theta}, \varepsilon_{z}, \gamma_{\theta_{z}}$ is respectively the hollow inclusion strain gauge measured hoop strain, axial strain and shear strain value; $K 1 \sim K_{4}$ are the correction coefficient.

Equations for the calculation of $K$ are:

$$
\begin{aligned}
& k_{1}=d_{1}\left(1-v_{1} v_{2}\right)\left[1-2 v_{1}+\frac{R_{1}^{2}}{\rho^{2}}\right]+v_{1} v_{2} ; \\
& k_{2}=\left(1-v_{1}\right) d_{2} \rho^{2}+d_{3}+v_{1} \frac{d_{4}}{\rho_{2}}+\frac{d_{5}}{\rho^{4}} ; \\
& k_{3}=d_{6}\left(1+\frac{R_{1}^{2}}{\rho^{2}}\right) ; \\
& k_{4}=\left(v_{2}-v_{1}\right) d_{1}\left(1-2 v_{1}+\frac{R_{1}^{2}}{\rho^{2}}\right) v_{2}+\frac{v_{1}}{v_{2}} ;
\end{aligned}
$$

Where $d_{1}=\frac{1}{1-2 v_{1}+m^{2}+n\left(1-m^{2}\right)}$;

$$
\begin{aligned}
& d_{2}=\frac{12(1-n) m^{2}\left(1-m^{2}\right)}{R_{2}^{2} D} ; \\
& d_{3}=\frac{1}{D}\left[m^{4}\left(4 m^{2}-3\right)(1-n)+x_{1}+n\right] ; \\
& d_{4}=\frac{-4 R_{1}^{2}}{D}\left[m^{6}(1-n)+x_{1}+n\right]
\end{aligned}
$$

$$
\begin{aligned}
& d_{5}=\frac{3 R_{1}^{4}}{D}\left[m^{4}(1-n)+x_{1}+n\right] ; \\
& d_{6}=\frac{1}{1+m^{2}+n\left(1-m^{2}\right)} ; \\
& n=G_{1} / G_{2} ; \quad m=R_{1} / R_{2} ; \\
& D=\left(1+x_{2} n\right)\left[x_{1}+n+(1-n)\right. \\
& \left.\left(3 m^{2}-6 m^{4}+4 m^{6}\right)\right]+\left(x_{1}-x_{2} n\right) m^{2} \\
& {\left[(1-n) m^{6}+\left(x_{1}+n\right)\right]} \\
& x_{1}=3-4 v_{1} ; \quad x_{2}=3-4 v_{2} .
\end{aligned}
$$

Where $R_{1}$ is the hollow package radius in the body; $R_{2}$ is the installation of the pore radius; $G_{1}$ is the hollow inclusion material shear modulus of epoxy resin; $G_{2}$ is the shear modulus of the rock; $v_{1}$ is the hollow inclusion material Poisson's ratio of epoxy resin; $v_{2}$ is the Poisson's ratio of the rock and $\rho$ is the resistance strain gauge in the hollow inclusion of radial distance. This method can be operated easily and adapt to poor integrity rock mass, and has a high success ratio. But there are still errors on the accuracy. Studies show that the precision of ground stress measurement is influenced not only by the drilling sites, rock mechanics properties, drillings speed, temperature, but also by the structure of strain gauge itself. Strain gauge are built-in epoxy resin layer, its feeling of the strain of drilling rock will go through the epoxy resin layer. Thus, the accuracy depends on the radius of drilling hole, strain gauge radius, the radius of the strain gauge's built-in parts and the elastic constants of surrounding rock and epoxy resin layer, namely the correction coefficients in the formula $K_{i}(i=1 \sim 4)$. Reference [9] pointed out that the error of stress component, which is main caused by the value $K_{1}$, and radius of drilling hole $\mathrm{R}$ has a comprehensive effect on $K_{1}$, but it did not explain the influence degree of drilling hole radius to $K_{1}$ and the final results. In order to definite the influence degree, improving the accuracy and the reliability of stress 
relief method, this paper will research the process of stress relief by numerical simulation method.

\section{The research on hollow inclusion stress relief} process with numerical simulation

\subsection{Establishment of numerical model}

Utilizing the calculation software of FLAC3D to simulate and discuss the influence degree of the drilling aperture ratio on the measuring accuracy. The size of the model is $53.2 \mathrm{~cm} \times 300 \mathrm{~cm} \times 53.2 \mathrm{~cm}$, the rock formation is linear elastic, homogeneous and isotropic, and the needing mechanical parameters are shown is table 1 .

Table 1 Mechanical Parameters

\begin{tabular}{ccc}
\hline $\begin{array}{c}\text { Mechanical } \\
\text { Parameters }\end{array}$ & Rock & $\begin{array}{c}\text { Epoxy resin } \\
\text { layer }\end{array}$ \\
\hline$E / G P a$ & 22.350 & 3 \\
$\mu$ & 0.27 & 0.36 \\
\hline
\end{tabular}

The bottom, left and right of the model is fixed, the drilling side is free surface, and applying $25 \mathrm{MPa}$ pressure on the top(Fig. 3 is the model). The parameters remain unchanged, except the radius of holes.

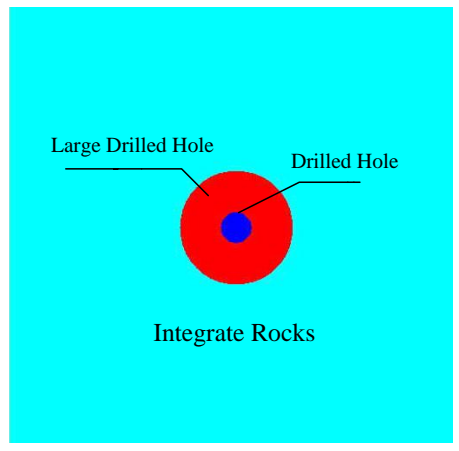

(a) Sectional View of The Model

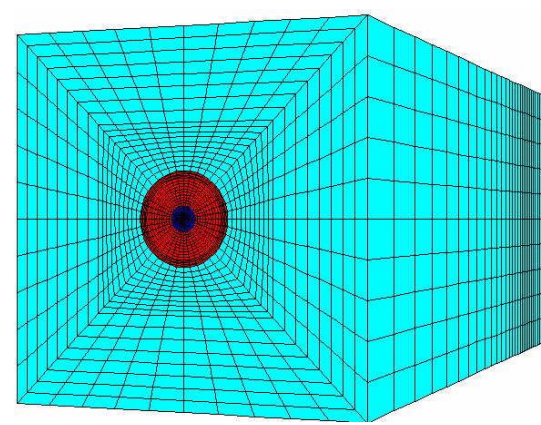

(b) Model of Computing Grid

Fig.3 Three - dimensional Calculation Model for Stress Relief

\subsection{The process of stress relief simulation}

According to the field measurements, the simulation process is divided into five steps, including: 1) Drilling the large hole, its radius is $133 \mathrm{~mm}$ and the depth is $130 \mathrm{~cm}$; 2) Drilling the small hole, the depth is $40 \mathrm{~cm}$ and its radius is changed under different circumstances; 3) Setting the hollow inclusion strain cells, the reference [6] shows that the ring compress of CSIRO cells' resin layer, supporting the hole wall, should be considered, the shell structure is used to simulate the resistance of resin layer; 4) Stress relief, the stress is relieved along the direction of the large hole, calculating balance every $2 \mathrm{~cm}$, and recording the displacement of the measuring point until it has not obvious change. Along the depth of the small hole, measuring points for monitoring displacement is arranged every $5 \mathrm{~cm}$, points' arrangements are shown in Fig.4.

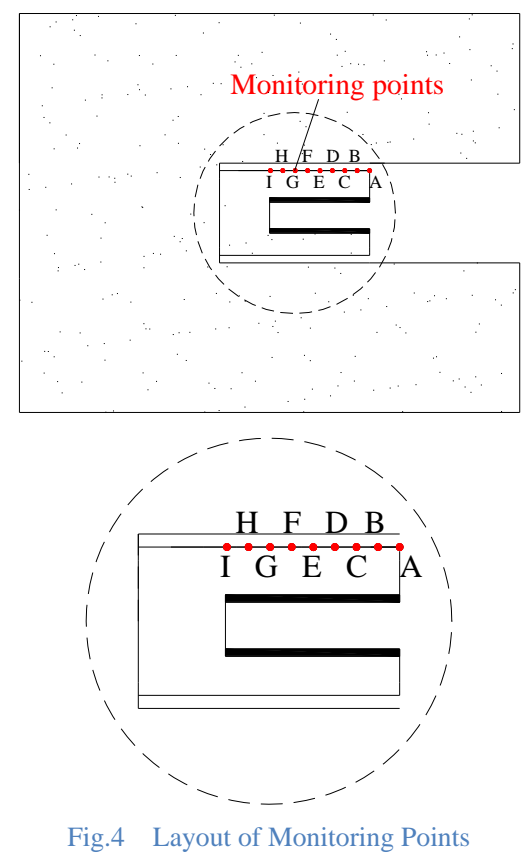

\subsection{Measuring points' simulation results}

In the second step of the simulation to change the radius of the hole, respectively took $0 \mathrm{~mm}$ ( that is, no drill holes), $10 \mathrm{~mm}, 12 \mathrm{~mm}, 14 \mathrm{~mm}, 16 \mathrm{~mm}, 18 \mathrm{~mm}, 20 \mathrm{~mm}, 22 \mathrm{~mm}$, $24 \mathrm{~mm}, 26 \mathrm{~mm}$.Fig.5 is the 9 point circumferential displacement curve when the radius is $26 \mathrm{~mm}$, the trends of circumferential displacement are similar when radius changed, they are not listed subject to the length. 
Using $\alpha$ presents the ratio between the distance from the hole and the hole radius ratio. Analyzed the data, the detail is shown in table 2 and Fig.6. It can be seen that the trend of displacement measuring point is hardly affected by the drilling radius; on the whole, the measured displacements near the hole are changed largely. With increasing depth of the measuring point, the displacement difference gradually reduced small and stabilizes. In actual measurement, strain gauges should make the work area in the stable area of displacement as much as possible and ensure data more accurate.

Table 2 The Ratio of The Distance Measuring Point With The Holes' Radius

\begin{tabular}{|c|c|c|c|c|c|c|c|c|c|}
\hline $\begin{array}{l}\text { Distance } \\
\text { form the } \\
\text { hole/cm }\end{array}$ & 0 & 5 & 10 & 15 & 20 & 25 & 30 & 35 & 40 \\
\hline$\alpha$ & 0 & 0.125 & 0.25 & 0.375 & 0.5 & 0.625 & 0.75 & 0.875 & 1 \\
\hline $\begin{array}{c}\text { Measuring } \\
\text { displacement } \\
/ \times 10^{-2} \mathrm{~mm}\end{array}$ & 10.4 & 7.63 & 5.14 & 4.4 & 3.83 & 3.65 & 3.61 & 3.66 & 4.29 \\
\hline
\end{tabular}

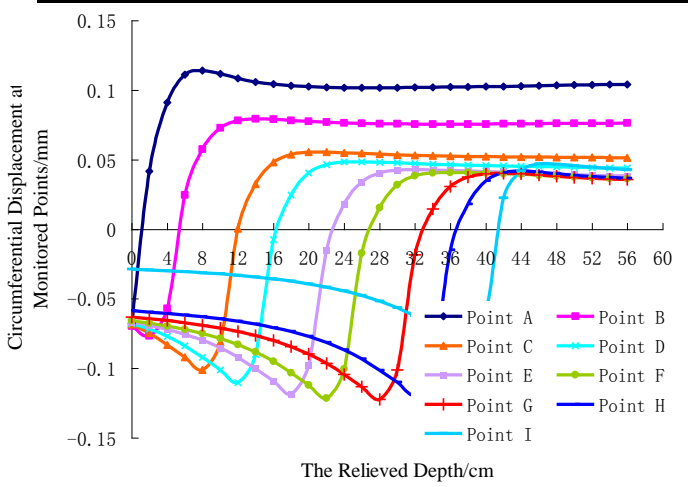

Fig.5 Measuring Displacement of Different point

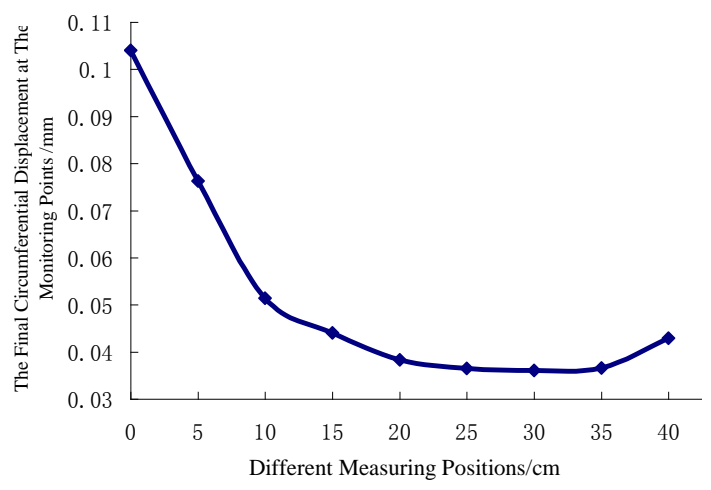

Fig.6 Variation of Circumferential

Displacement With Measuring Point

\subsection{Aperture ratio analysis of simulation results}

In order to define the drilling aperture ratio on the measurement results and seek the most reasonable way of measuring, measuring point displacements under different aperture ratio is analyzed.Fig.7 reflects the changed trend of monitoring displacement under different aperture ratio during the stress relieving process.

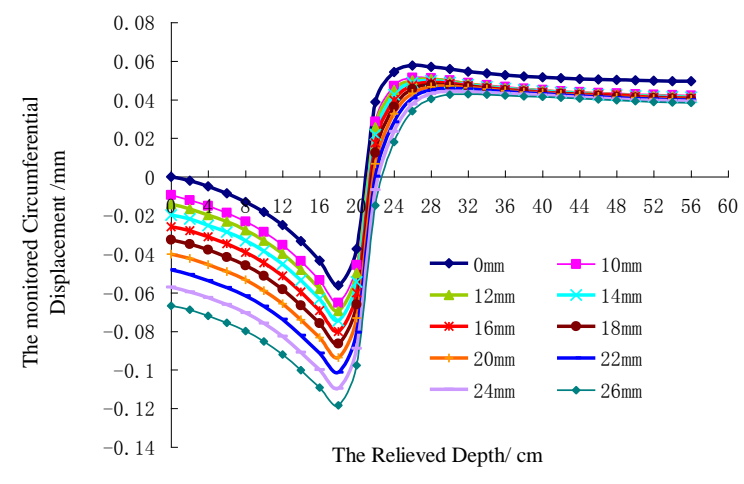

Fig.7 The Circumferential Displacement in The Different Aperture Ratio

As can be seen from the figure, the whole process of stress relief can be divided into three stages. When relieved depth did not reach monitoring, circumferential displacement moves along the radius direction to the center, which led by stress transfer, and it is equivalent to excavation effect. When relieved depth close to the monitoring point, along the circumferential displacement into the direction of the radius outward growth, the core outward expansion; and the third phase is when relieved depth reaches a certain value, displacement gradually stabilized, suggested that the stress on the core has been completely released.

Analysis the curve under the different aperture ratio , which can be found that part of the displacement in 
the process of drilling had lost and could not be monitored by the strain gauge .Using $\beta$ represents the losing displacement, then

$$
\beta=\left(1-\frac{u_{i}}{u_{0}}\right) \times 100 \%
$$

Where $u_{i}$ is the displacement in different aperture ratio; $u_{0}$ is the displacement in no hole.

Analyzed the data and the results are shown in Table 3 and Fig.8. With the increase of r, the error caused by the drilling hole will decrease. Through the expression of $\mathrm{K}_{1}, \mathrm{~K}_{1}$ 's value will decrease when $\mathrm{r}$ increases, then according to the formula (1) the calculation of the stress will increase accordingly. Therefore a direct result of stress measurement is lower when $\mathrm{r}$ smaller, also suggests that thick holes is conducive to improve the accuracy of measurement. To determine the loss of displacement by drilling holes, using Matlab to fit the curve, as shown in figure 9. After fitting, the curve equation is $\beta=0.5546 r^{(-1.856)}+0.06$, When $\mathrm{r}$ is determined according to the equation the measured data can be corrected. It can make displacement closer to the actual displacement; thereby can increasing the measurement accuracy.

Table 3 Displacement Error Caused by The Different Aperture Ratio

\begin{tabular}{ccccccccccc}
\hline Radius/mm & 0 & 10 & 12 & 14 & 16 & 18 & 20 & 22 & 24 & 26 \\
\hline $\begin{array}{c}\text { Aperture } \\
\text { Ratio }\end{array}$ & -- & 6.65 & 5.54 & 4.75 & 4.16 & 3.69 & 3.325 & 3.02 & 2.77 & 2.56 \\
$\begin{array}{c}\text { Stable } \\
\text { Displacement } \\
/ \times 10^{-2} \mathrm{~mm}\end{array}$ & 5.02 & 4.65 & 4.59 & 4.55 & 4.51 & 4.47 & 4.42 & 4.37 & 4.30 & 4.22 \\
$\beta$ & -- & 7.4 & 8.6 & 9.4 & 10.2 & 11.0 & 11.6 & 0.129 & 14.4 & 16.0 \\
\hline
\end{tabular}

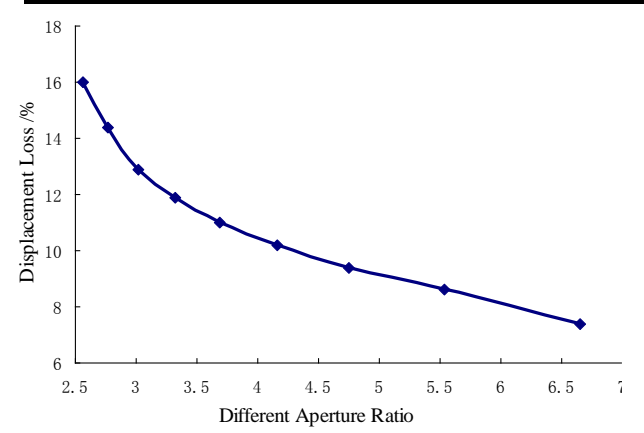

Fig.8 Effects of Different Aperture Ratio on Displacement

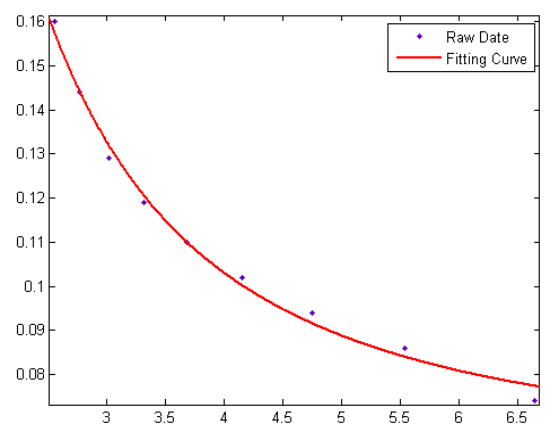

Fig9 Fitting Curve by Using Matlab
4 Analysis of geostress measurement results in the Datai mine

Information on stress measurement by Datai mine as an example of measurement error caused by drilling aperture ratio. The mine average surface elevation between 400 and $500 \mathrm{~m}$, geotress measurement level of observation point is located at $-510 \mathrm{~m}$ roadway, as shown in figure 10.

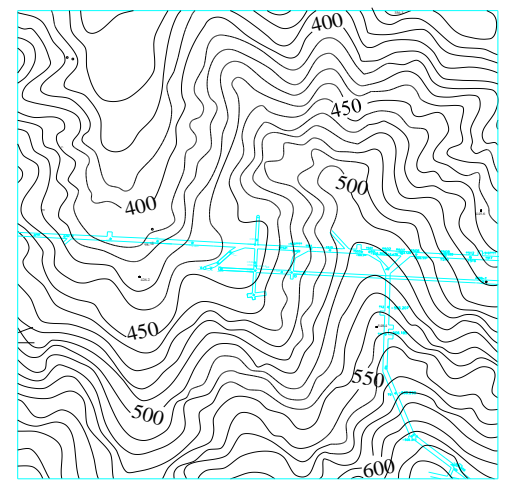

Fig 10 Topographic Map About Datai Mine 
The rock is diabase in geostress measurement section and is relatively hard. Measuring points are away from the stress concentrated area, mining - affected zone ,faults and other geological structure ${ }^{[10]}$, as shown in figure 11.Measuring method by using KX-81 hollow inclusion strain cells. Drilled large holes with a diameter of $133 \mathrm{~mm}$, the hole diameter is $36 \mathrm{~mm}$, the size of the hole radius ratio of 3.69.After installing the strain gauge about 24 hours for the curing of epoxy, stress relieving.

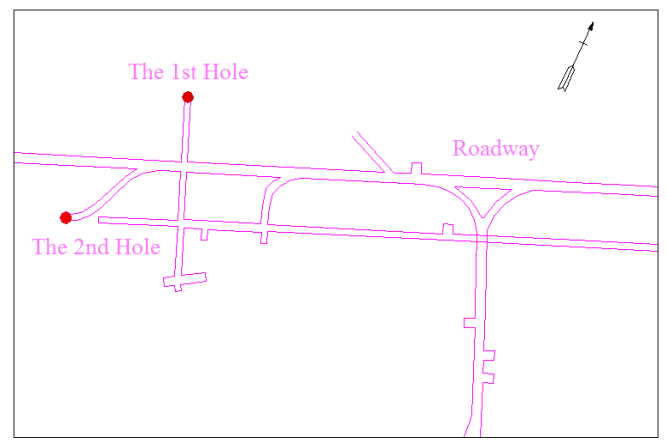

Fig11 Drill Hole Location

Table 4 The Stress Components of The Measuring Point

\begin{tabular}{cccccc}
\hline$\sigma_{x} / \mathrm{MPa}$ & $\sigma_{y} / \mathrm{MPa}$ & $\sigma_{z} / \mathrm{MPa}$ & $\tau_{x y} / \mathrm{MPa}$ & $\tau_{y z} / \mathrm{MPa}$ & $\tau_{x z} / \mathrm{MPa}$ \\
\hline 22.32 & 42.47 & 24.46 & -8.63 & 0.93 & -0.24 \\
\hline \multicolumn{5}{c}{ Table 5 } & Comparison of Error
\end{tabular}

Table 5 Comparison of Error

\begin{tabular}{ccccc}
\hline Theoretical Value/MPa & Measured Value/MPa & Measurement Error/\% & Correction/MPa & Correction Factor/\% \\
\hline 26.57 & 24.46 & 7.94 & 27.12 & 2.1 \\
\hline
\end{tabular}

\section{Conclusions}

Using hollow inclusion strain cells to measure the size and direction of geostress is one of the general methods, it is simple and adaptable. However, there are still some errors on the measurement accuracy. There are many reasons affecting the measurement accuracy, this paper analyzed the influence on the measurement accuracy with the placement of sensor, drilling aperture ratio.

(1) Arrangements of measuring positions are hardly effected by aperture ratio. It related to the location of the hole's depth. As the depth of the measuring point increase, displacement will be smaller by the position. Displacement difference can be ignored after the
In this paper, the simulation analysis shows that the measurement of displacement is less than the actual value in ratio, which in turn caused the geostress smaller. According to the measured strain data, measuring points and geometrical parameters of rock mechanics parameters, calculated by the Institute of Geomechanics, Chinese Academy of Geological Sciences Stress of dedicated software, as shown in table 4. Using the modified formula correct measurement results, when $\mathrm{r}=3.69, \beta=0.109$, then the result is 27.12Mpa. According to the drilling of the mine area histogram and the rock density ${ }^{[11]}$, vertical stress and $\sigma_{z}=\gamma H$,the theoretical value is $26.57 \mathrm{MPa}$. The measured and calculated values, are shown in table 5 . The measured geostress is less than the theoretical value. It verified the correctness of simulation conclusions. Errors can be reduced by amending the measured results and improve the precision of measurement 
In addition, the analysis of the drilling aperture ratio on measurement accuracy of this paper is limited to numerical simulation .It needs further study.

\section{Acknowledgements}

This work is financially by the deep mining of coal mine ground pressure control in Heilongjiang Province and the opening of gas control key laboratory of fund projects(F2313-09); Shandong University of Science and Technology Science Fund for Distinguished Young(2011KYJQ106);Construction of Special Fund for "Taishan Scholars" in Shandong Province.

\section{References}

[1] JING Feng, SHENG Qian, ZHANG Yong-hui and LIU Yuan-kun, Study advance on in-site geostress measurement and analysis of initial geostress field in China, Rock and Soil Mechanics, ,Vol.32,Supp2,Pp 51-58, 2011.

[2] QIN Xiang-hui, TAN Cheng-xuan , SUN Jin-zhong , CHEN Qun-ce and AN Mei-jian, Experimental study of relation between in-situ crustal stress and rock elastic modulus, Rock and Soil Mechanics ,Vol.33,No.6,Pp 1689-1695,2012.

[3] BAI Jinpeng, PENG Hua, MA Xiumin, JIANG Jingjie and LI Zhen, Hollow inclusion strain gauge geostress measuring instrument in deep borehole and its application example, Chinese Journal of Rock Mechanics and Engineering, Vol.32, No.5, Pp 902-908, 2013

[4] CAI Mei-feng, QIAO Lan, YU Jin-po, Problems on Accuracy of Hollow Inclusion Strain Cells, Yan Tu Gong Cheng Xue Bao, Vol.16, No.6, Pp 15-20,1994.

[5] OUYANG Zhenhua, CAIMeifeng, WANG Shuanghong,MIAO Shen-jun, Borehole overcoring technique and its application, The Eighth National Rock Mechanics and Engineering Academic Conference Proceedings, Pp, 936-939.

[6] LI Yuan, QIAO Lan, SUN Xinshuo, Analyses of Some Factors Affecting Precision in in-situstress Measurement With Method of CSIRO cells, Chinese Journal of Rock Mechanics and Engineering,Vol.25,No.10,Pp 2140-2144,2006.
[7] ZHAO Liwang, LIU Tian peng, LI Kemian , LI Junfu and ZHANG Wendong, Anslyses of the Confining Pressure Formulation About Geostress Measurement With Method of Csird Cells, Water Conservancy Science and Technology and Economy, Vol.18,No.10,Pp 42-44,2012.

[8] WANG Jiashuo,DOU Linming,Yang Zengqian ,ZHANG Runbin and LI Zhenle,Application of hollow inclusion technique to geostrrss measurment in Aiweiergou Coal Mine, Coal science and technology,Pp 40-43,2013.

[9] LIU Yunfang, ZHU Jiebing, LIU Yuankun, Research on hollow inclusion triaxial strain gauge for geostress measurement, Chinese Journal of Rock Mechanics and Engineering, ,Vol.20,No.4,Pp 448-453,2001.

[10] ZHAO Tongbin, TAN Yunliang, ZHANG Ze, Geomechanical mechanism of rock burst in deep level of Datai Mine , Journal of ChinaCoal Ssociety, Vol.35, No.12, Pp 2039-2044,2010.

[11] ZHANG Ze ,Analysis on the original rock stress and geomechanics gauses of rock burst in the datai mine ,Shandong University of Science and Technology ,2010. 